\title{
A New Management Book: "How we Manage? Between Amateurism and Professionalism"
}

\section{Cezar-Petre SIMION ${ }^{1}$}

\begin{abstract}
Keywords: management, methods, methodologies.
\end{abstract}
JEL classification: M10, M19

DOI: $10.24818 /$ RMCI.2018.5.531

The book How we manage? Between amateurism and professionalism" published in July 2018 by the University Publishing House, bears the signature of a well-known management specialist, Prof. Ion Verboncu, PhD, Academy of Economic Studies of Bucharest.

Mr. Verboncu's activity is well-known - author and co-author of more than 65 papers, over 200 articles published in specialized journals, mostly in BDIindexed journals, scientific communications at national and international conferences (approximately 100) - and a guarantee of the quality of any "product" that bears its name. All these are the result of laborious scientific research conducted over 40 years and represent a real "visiting card" of the university professor Ion Verboncu, teacher of generations of economists and trainer of numerous managers from the Romanian public enterprises and institutions.

The paper we are examining deals with, in the 464 pages, a problem of great interest for the management theory and practice in Romania, focused on managerial methodologies, namely the promotion and use of managerial methods, techniques and methodologies as an important way of professionalizing managers and management. The premise of the author is that, at the level of the organizations, of the Romanian economy and society, there are significant deviations from other European Union countries, caused mainly by the poor management exercised. The phrase launched by American specialist Peter Drucker decades ago that "there are no rich countries and poor countries, but well-led and badly led countries" can be translated at the level of organizations where, unfortunately, the poor quality and efficiency of management is reflected in the economic results obtained. In the context of promoting truly scientific management, methodologies are shaped as a dual-role solution: on the one hand, it helps to professionalize those who run and manage public and private enterprises

Cezar-Petre Simion, The Bucharest University of Economic Studies,
cezar.simion@man.ase.ro 
or public institutions and, on the other hand, contributes directly to streamlining management as a whole, along with the generalized promotion of strategic management, managerial reengineering, improvement of organizational culture.

The book addresses the first managers of all organizational echelons of the organization and brings to their attention elements of methodological novelty, as follows: a new methodology of managerial reengineering, which takes into account some important milestones in the performance of an organization - objectives, processes, structures, people (managers and executors), results, a different view on the quality and efficiency of management and methodological mechanisms for their evaluation, a complex approach to profit center management, diagnosis, delegation, meeting and benchmarking, as well as a new concept in terms of professionalization of managers.

All these aspects are systematically treated and provide the reader with the necessary tools for a critical, objective judgment of what is happening today in Romanian management. Scientific arguments resulting from the author's research work or from the many bibliographic sources consulted give the paper its specificity, originality and novelty. We strongly recommend it to those who want to discover new horizons of knowledge in the field of management. 